\title{
Article \\ Controlling the Spatiotemporal Release of Nerve Growth Factor by Chitosan/Polycaprolactone Conduits for Use in Peripheral Nerve Regeneration
}

\author{
Katarzyna Nawrotek ${ }^{1, * \mathbb{D}}$, Monika Kubicka ${ }^{1}$, Justyna Gatkowska ${ }^{2} \mathbb{D}$, Marek Wieczorek $^{3}$, Sylwia Michlewska ${ }^{4} \mathbb{D}$, \\ Adrian Bekier ${ }^{2}$ (D), Radosław Wach ${ }^{5}$ and Karolina Rudnicka ${ }^{6, *}$ D
}

Citation: Nawrotek, K.; Kubicka, M.; Gatkowska, J.; Wieczorek, M.;

Michlewska, S.; Bekier, A.; Wach, R.; Rudnicka, K. Controlling the Spatiotemporal Release of Nerve Growth Factor by Chitosan/

Polycaprolactone Conduits for Use in Peripheral Nerve Regeneration. Int. J. Mol. Sci. 2022, 23, 2852. https:// doi.org/10.3390/ijms23052852

Academic Editors: Ralf Smeets and Anders Henningsen

Received: 3 February 2022

Accepted: 3 March 2022

Published: 5 March 2022

Publisher's Note: MDPI stays neutral with regard to jurisdictional claims in published maps and institutional affiliations.

Copyright: (C) 2022 by the authors. Licensee MDPI, Basel, Switzerland. This article is an open access article distributed under the terms and conditions of the Creative Commons Attribution (CC BY) license (https:// creativecommons.org/licenses/by/ $4.0 /)$.
1 Department of Environmental Engineering, Faculty of Process and Environmental Engineering, Lodz University of Technology, 213 Wolczanska Street, 90-924 Lodz, Poland; monika.kubicka@p.lodz.pl

2 Department of Molecular Microbiology, Faculty of Biology and Environmental Protection, University of Lodz, 12/16 Banacha Street, 90-237 Lodz, Poland; justyna.gatkowska@biol.uni.lodz.pl (J.G.); adrian.bekier@biol.uni.lodz.pl (A.B.)

3 Department of Neurobiology, Faculty of Biology and Environmental Protection, University of Lodz, 141/143 Pomorska Street, 90-236 Lodz, Poland; marek.wieczorek@biol.uni.lodz.pl

4 Laboratory of Microscopic Imaging and Specialized Biological Techniques, Faculty of Biology and Environmental Protection, University of Lodz, 12/16 Banacha Street, 90-237 Lodz, Poland; sylwia.michlewska@biol.uni.lodz.pl

5 Faculty of Chemistry, Institute of Applied Radiation Chemistry, Lodz University of Technology, 15 Wroblewskiego Street, 93-590 Lodz, Poland; radoslaw.wach@p.lodz.pl

6 Department of Immunology and Infectious Biology, Faculty of Biology and Environmental Protection, University of Lodz, 12/16 Banacha Street, 90-237 Lodz, Poland

* Correspondence: katarzyna.nawrotek@p.lodz.pl (K.N.); karolina.rudnicka@biol.uni.lodz.pl (K.R.); Tel.: +48-42-6313996 (K.N.); +48-42-6355606 (K.R.)

Abstract: Tubular polymeric structures have been recognized in the treatment of peripheral nerves as comparable to autologous grafting. The best therapeutic outcomes are obtained with conduits releasing therapeutic molecules. In this study, a new approach for the incorporation of biologically active agent-loaded microspheres into the structure of chitosan/polycaprolactone conduits was developed. The support of a polycaprolactone helix formed by 3D melt extrusion was coated with dopamine in order to adsorb nerve growth factor-loaded microspheres. The complex analysis of the influence of process factors on the coverage efficiency of polycaprolactone helix by nerve grow factorloaded microspheres was analyzed. Thus, the PCL helix characterized with the highest adsorption of microspheres was subjected to nerve growth factor release studies, and finally incorporated into chitosan hydrogel deposit through the process of electrophoretic deposition. It was demonstrated by chemical and physical tests that the chitosan/polycaprolactone conduit meets the requirements imposed on peripheral nerve implants, particularly mimicking mechanical properties of surrounding soft tissue. Moreover, the conduit may support regrowing nerves for a prolonged period, as its structure and integrity persist upon incubation in lysozyme-contained PBS solution up to 28 days at body temperature. In vitro cytocompatibility toward mHippoE-18 embryonic hippocampal cells of the chitosan/polycaprolactone conduit was proven. Most importantly, the developed conduits stimulate axonal growth and support monocyte activation, the latter is advantageous especially at early stages of nerve regeneration. It was demonstrated that, through the described approach for controlling spatiotemporal release of nerve growth factors, these biocompatible structures adjusted to the specific peripheral nerve injury case can be manufactured.

Keywords: electrodeposition; 3D printing; chitosan; conduit; peripheral nerve regeneration

\section{Introduction}

A peripheral nerve injury (PNI) relates to damage, crushing, or transection of the peripheral nerve. It is estimated that $3 \%$ of all critical trauma patients present some form of 
nerve defect $[1,2]$. Moreover, PNIs can result from degenerative changes or inflammatory diseases [3,4]. Peripheral nerves are key connections among the brain, spinal cord, and body. This highly complex network provides control over sensation, movement, and motor coordination. Treatment of damaged peripheral nerve tissue may be pharmacologic, by transplantation (i.e., autografting, allografting, or xenografting) or by the implantation of nerve guidance conduits (NGCs) to bridge the nerve stumps, providing room and environment for nerve regeneration [5-8]. Conventional pharmacologic therapy is performed in the early stages of damage caused by inflammation. Transplantation is a complex procedure, with a risk of graft rejection, as well as complications (e.g., infection). Therefore, innovative solutions allowing for re-generation of damaged tissues with the use of NGCs are being sought.

Nerve guidance conduits should serve as a platform stimulating nerve regeneration at lesion sites [9]. Their main functions are to induce the proper orientation of axon growth from the proximal end of the nerve, to accumulate growth factors secreted by damaged nerve stumps within its lumen, and to prevent scar tissue growth within the lesion site [10-13]. In addition to biocompatibility, a desired characteristic of the conduits is biodegradability $[14,15]$. The guidance of axons is evoked by controlled release of biologically active substances (e.g., neurotrophic factors) from the structure of the NGC $[16,17]$. Preferentially, the active agents should be incorporated in the NGC in a gradient manner $[18,19]$. Neurotrophic factors are characterized with a short in vivo half-life. Moreover, they impede axonal regeneration when used in supraphysiological doses. Therefore, different approaches to counteract these phenomena have been developed [20]. One of the most studied ones is encapsulation of hydrophilic molecules such as proteins or nucleic acids within a polymer [21-23]. Encapsulation requires proper selection of polymeric composition and optimization of synthesis parameters in order to ensure the highest possible encapsulation efficiency while maintaining the biological activity of the encapsulated biomolecule [24]. In the last few years, numerous publications have mentioned delivery systems of bone morphogenetic protein 2 (BMP2) or growth factors (GF) using polymeric particles [25]. Polymeric microspheres seem to be a promising method to control the release of biologically active substances.

A technology for obtaining chitosan/polycaprolactone nerve guidance conduits, which employs polymer extrusion and electrophoretic deposition, was developed in our laboratory [8]. The fabricated structures were made of two layers: polycaprolactone (PCL) helix and chitosan $(\mathrm{CH})$ hydrogel deposit. In this work, the surface of the PCL helix was covered by dopamine. Such modification allowed the adsorption of microspheres; thus, it could serve as a platform for the controlled release of biologically active substances. Since the PCL helix can be characterized by different pitch, the concentration of active agents could be regulated. Moreover, the pitch can be constant or gradient. The first part of this work was to study the influence of different process parameters on the coverage efficiency of the PCL helix by nerve grow factor-loaded microspheres (NGF- $\mu \mathrm{S}$ ), such as the influence of microsphere dimensions, the effect of dopamine and microsphere concentration, and the release profile of NGF from NGF- $\mu$ / PCL helices, determined by enzyme-linked immunosorbent assay (ELISA), was monitored over a period of 14 days. In the second part, the PCL helix covered by nerve grow factor-loaded microparticles was incorporated into the $\mathrm{CH}$ hydrogel by electrophoretic deposition. Subsequently, chemical, physical, and mechanical properties of conduits and their stability in enzymatic environment were evaluated. Lastly, in vitro cell studies were conducted for cytocompatibility evaluation and to assess axonal growth of hippocampal cells and nuclear factor (NF-KB) activation in THP1-Blue ${ }^{\mathrm{TM}}$ NF- $\mathrm{kB}$ monocytes. It is anticipated that the obtained structures will find application as implants in tissue engineering of the peripheral nervous system. The developed method of incorporation of polymeric microspheres into the structure of chitosan/polycaprolactone nerve guidance conduits may contribute to progress in regeneration of damaged nervous tissue by facilitating axonal guidance inside the conduit lumen. 


\section{Results and Discussion}

\subsection{Characterization of Microspheres and Their Adsorption to Polycaprolactone Filament}

The first step of the work aimed at covering the PCL helix with dopamine in order to allow adsorption of NGF-loaded microspheres (NGF- $\mu S$ ). Poly(lactide-co-glycolide) (PLGA) encapsulating NGF microcapsules were prepared by the water-in-oil-in-water $(\mathrm{W} / \mathrm{O} / \mathrm{W})$ method with poly(vinyl alcohol) (PVA) as a stabilizer in the external aqueous phase as previously described [26,27]. The main advantage of the $\mathrm{W} / \mathrm{O} / \mathrm{W}$ dispersion method is the maintenance of bioactivity of the encapsulated biologically active substances. The properties of microspheres produced by this method depend on the concentrations of PLGA and stabilizing polymer, emulsification volumes, emulsification energy applied, viscosities of the different phases, and additives [28].

For optimization studies, microspheres were prepared without NGF $(\mu S)$. Firstly, the influence of microsphere diameter on adsorption efficiency was determined. For this purpose, three concentrations of poly(lactide-co-glycolide) in dichloromethane (20\%, 25\%, and $40 \%$ ) were applied. Figure 1 shows the variety of microsphere diameters depending on concentration of PLGA in dichloromethane (DCM).

A

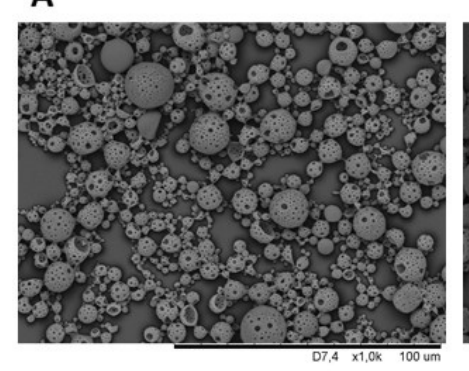

B

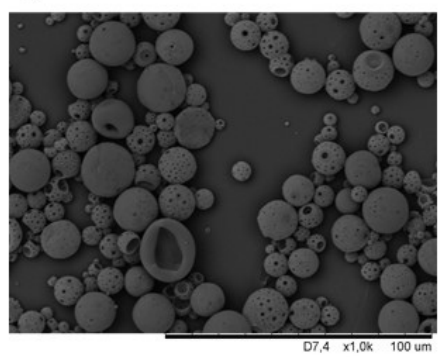

C

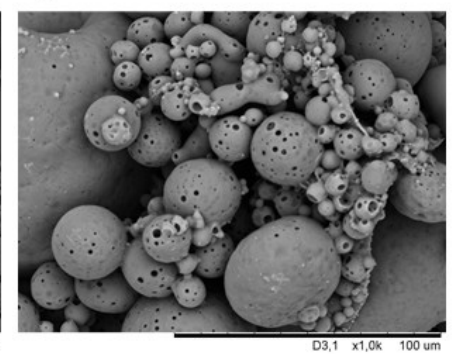

D

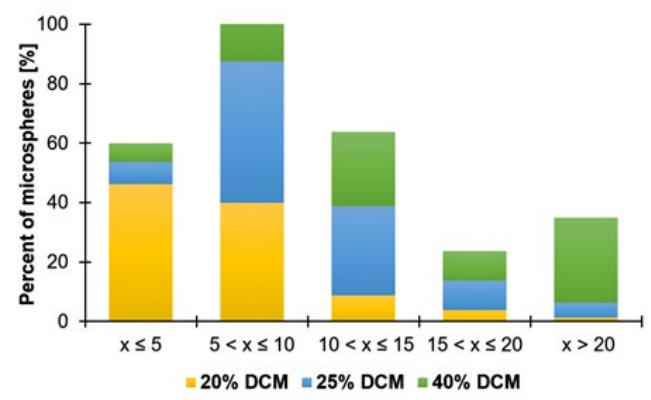

Figure 1. Scanning electron microscope images of microspheres obtained by water-in-oil-in-water method using (A) 20\%, (B) 25\%, and (C) 40\% poly(lactide-co-glycolide) in dichloromethane. (D) Variety of microsphere diameters depending on concentration of PLGA in DCM.

The PCL helices covered by dopamine showed different adsorption efficiency of microspheres depending on their average diameters (Figure 2A). The highest adsorption was observed for microspheres prepared from solution containing 20\% PLGA in DCM. In this case, $46.3 \%$ of microspheres prepared applying these conditions were characterized with a diameter not higher than $5 \mu \mathrm{m}$. This concentration was used in the next optimization steps. In the next step of the work, the influence of dopamine concentration on microsphere adsorption was studied. Figure 2B shows adsorption of microspheres on PCL helices modified in a solution of $0.2 \%, 0.4 \%$, and $0.6 \%$ dopamine hydrochloride. The highest adsorption was observed for PCL filament modified in a solution of $0.4 \%$ dopamine hydrochloride, and this condition was used in the next step. The final optimization step aimed at determining the influence of microsphere concentration on adsorption efficiency. A higher microsphere concentration resulted in a higher adsorption (Figure 2C). 
a

A

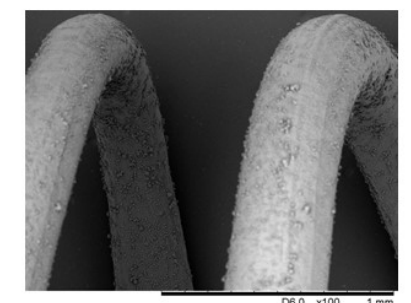

d

B

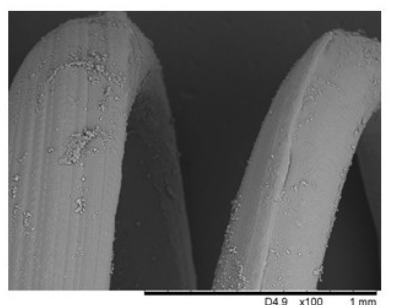

g

C

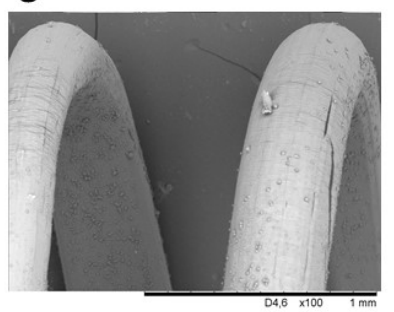

b

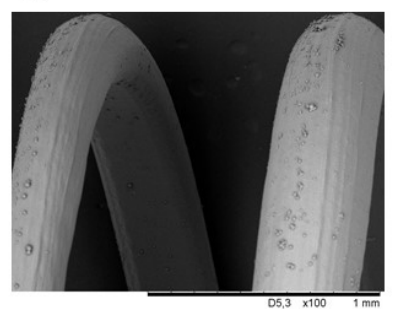

e

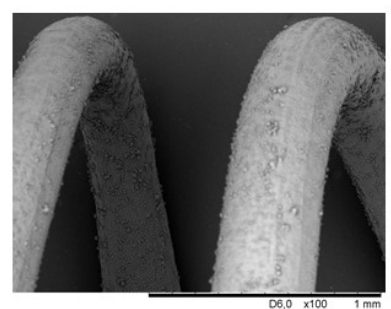

h

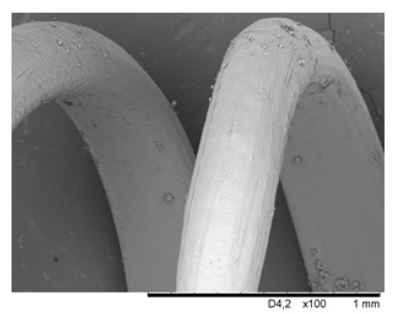

c

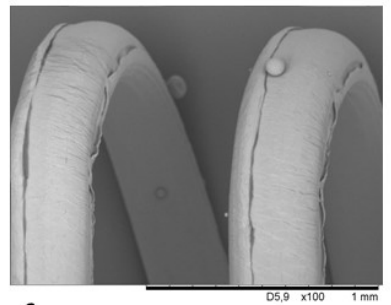

f

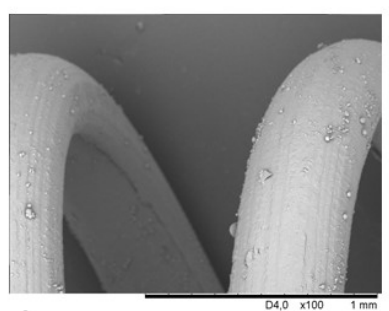

i

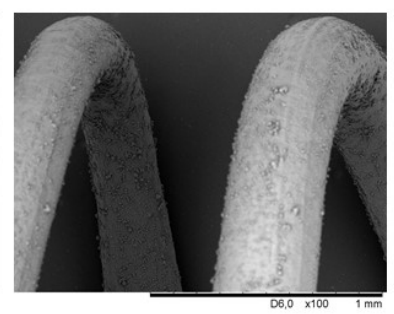

Figure 2. Scanning electron microscope images illustrating the influence of (A) concentration of PLGA in DCM ((a) 20\%, (b) 25\%, and (c) 40\%), (B) dopamine concentration ((d) $0.2 \%$, (e) $0.4 \%$, and (f) $0.6 \%$, and (C) microsphere concentration ((g) $1.19 \%$, (h) $1.50 \%$, and (i) $2.34 \%$ ) on microsphere adsorption efficiency to PCL helix.

On the basis of the optimization studies, the conditions leading to the highest adsorption efficiency were determined. Firstly, the microspheres should be prepared from a solution containing 20\% PLGA in DCM. Secondly, the surface of the PCL helix should be modified in solution containing $0.4 \%$ dopamine hydrochloride. Lastly, the modified PCL helix should be exposed to the solution containing $2.3 \%$ microspheres.

\subsection{Kinetics of NGF Release from NGF- $\mu S / P C L$ Helix}

The NGF- $\mu$ S/PCL helix was prepared under the conditions selected in the previous experiment. The release profile of NGF from NGF- $\mu$ S/PCL helices, determined by NGF ELISA, over a period of 14 days is shown in Figure 3. After an initial burst, $267.0 \pm 58.6 \mathrm{pg} / \mathrm{cm}$ of NGF from $1 \mathrm{~cm}$ of NGF- $\mu \mathrm{S} / \mathrm{PCL}$ helix was released. After 14 days of the study, $407.8 \pm 151.7 \mathrm{pg}$ of encapsulated NGF from $1 \mathrm{~cm}$ of NGF- $\mu$ S/PCL helix was released. The kinetics of the NGF release corresponds to that obtained in the literature [19].

The release of therapeutic molecules from PLGA microspheres is dependent on the physicochemical characteristics of the encapsulated molecule and created interaction (i.e., ionic, hydrophobic, adsorption, etc.) with the PLGA matrix during preparation [28]. Therapeutic molecule release kinetics is also dependent on the molecular weight of the PLGA used. The lower molecular weight of PLGA results in faster release [29]. It is a consequence of less physical entanglement between the polymer chains and more rapid pore formation during initial hydration and quick hydrolytic degradation of 50:50 lactideglycolide copolymer. 


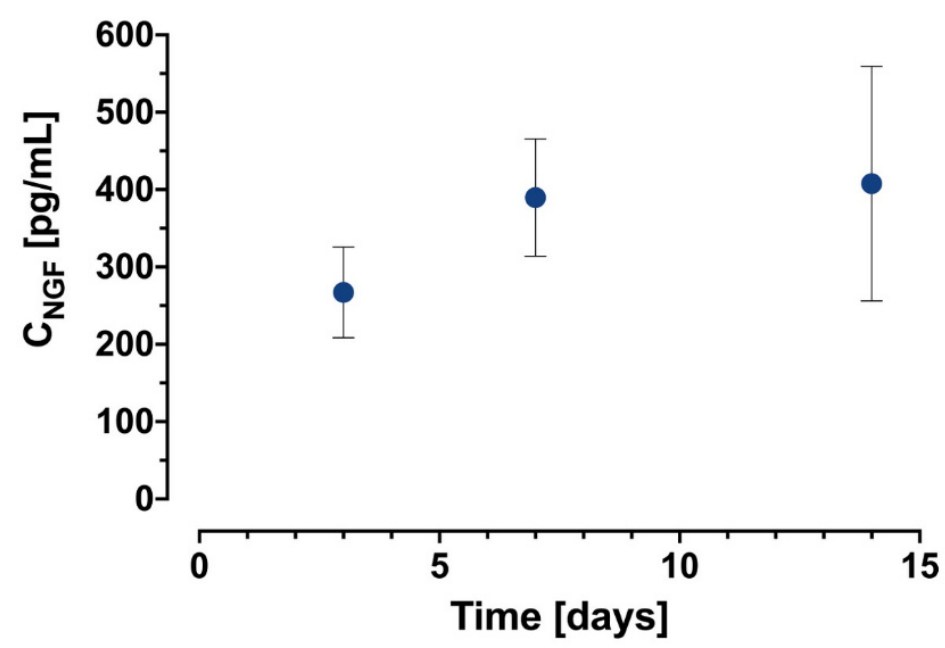

Figure 3. Cumulative release profile of NGF (pg/cm of NGF- $\mathrm{S} / \mathrm{PCL}$ helix) over a 14 day period from $\mu \mathrm{S} / \mathrm{PCL}$ helix.

Therapeutic molecule release from PLGA microspheres prepared by the $\mathrm{W} / \mathrm{O} / \mathrm{W}$ method with PVA as a stabilizer in the external aqueous phase is governed by diffusionand degradation-mediated release mechanisms [19]. The initial burst release is observed due to desorption of loosely attached therapeutic molecules in surface pores or near the surface of the microspheres. Upon losing the pore-filling or surface-bound proteins, the microsphere wall is characterized by an interconnecting porous network through which further therapeutic molecule release can take place.

\subsection{Incorporation of Polycaprolactone Filament into Hydrogel Chitosan Deposit}

The method developed in our laboratory allows extruding the PCL fiber in helix form with predefined geometry (i.e., pitch, fiber diameter) (Figure 4A) [8]. Moreover, the pitch can be constant or gradient (Figure $4 \mathrm{~A}$ ). In the previous section, a study on the microsphere adsorption efficiency to PCL helix was presented. NGF-loaded microspheres can be efficiently adsorbed onto PCL helix covered by dopamine (Figure 4B). Furthermore, the NGF- $\mu$ S/PCL helix can be covered by chitosan hydrogel deposit in the process of electrophoretic deposition to obtain a tubular conduit (Figure 4C).

A

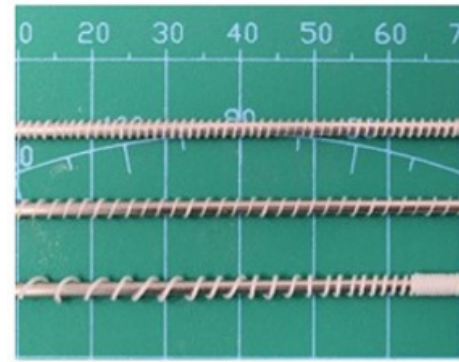

B

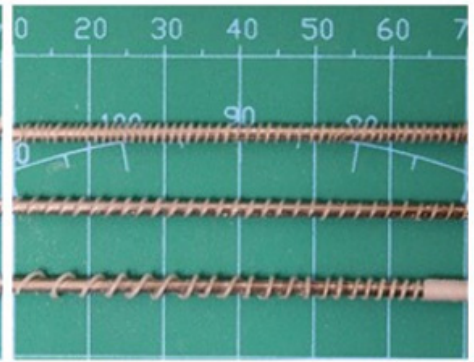

C

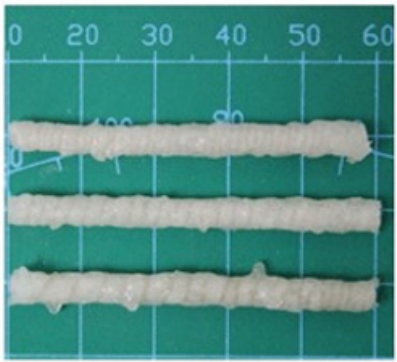

Figure 4. (A) PCL helix can be extruded with predefined geometry, constant or gradient pitch. (B) NGF-loaded microspheres can be successfully adsorbed to PCL helix covered by dopamine. (C) NGF- $\mu \mathrm{S} / \mathrm{PCL}$ helix can be covered by chitosan hydrogel deposit in the process of electrophoretic deposition.

\subsection{Structural Characterization of the Chitosan/Polycaprolactone Implants}

The electrodeposition process is carried out in a cylindrical reactor made of stainless steel. The NGF- $\mu \mathrm{S} / \mathrm{PCL}$ helix is mounted onto a rod with predefined diameter corresponding to helix diameter, which serves as a cathode. The solution of electrically charged polymers is obtained by dissolving chitosan, hydroxyapatite, and sodium hyaluronate 
in an aqueous solution of lactic acid. Under the influence of the acidic environment, the amino groups of chitosan are protonated by hydronium ions $\left(\mathrm{H}_{3} \mathrm{O}^{+}\right)$. Application of an electric current to the system results in the reduction of water at the surface of the cathode according to the following equation:

$$
2 \mathrm{H}_{2} \mathrm{O}+2 \bar{e} \rightarrow 2 \mathrm{OH}^{-}+\mathrm{H}_{2} .
$$

The above reaction starts the alkalization of the area surrounding the cathode by increasing the amount of hydroxyl ions. At the same time, hydrogen is released. This phenomenon leads to deprotonation of chitosan amino groups according to the following formula:

$$
\text { Chit }-\mathrm{NH}_{3}^{+}+\mathrm{OH}^{-} \rightarrow \text { Chit }-\mathrm{NH}_{2}+\mathrm{H}_{2} \text {. }
$$

The structure of the formed chitosan hydrogel deposit was irregular and porous due to gas evolution during electrodeposition (Figure 5A). The ideal material for implants intended for peripheral nerve tissue engineering should be in the form of a membrane allowing the diffusion of oxygen and nutrients into the regeneration site from interstitial fluid. On the other hand, conduit walls should constitute a barrier to the infiltration of inflammatory cells into the conduit lumen. The obtained composition of chitosan hydrogel deposit is favorable for the release of NGF from the NGF- $\mu$ S/PCL helix immersed in it.

In order to assess the interaction of compounds forming the chitosan hydrogel deposit, Fourier transform infrared spectroscopy (FTIR) spectroscopy was applied (Figure 5C). Chitosan moieties revealed peaks present at $1647 \mathrm{~cm}^{-1}$ (-C=O stretching mode), at $1580 \mathrm{~cm}^{-1}$ $\left(-\mathrm{NH}_{2}\right.$ bending mode), and three in the range from 1020 to $1140 \mathrm{~cm}^{-1}$ (C-O-C stretching asymmetric and symmetric mode) [29]. The peaks characteristic for moieties of hydroxyapatite $\left(\mathrm{PO}_{4}{ }^{3-}\right)$ could be distinguished at $1020,961,599$, and $561 \mathrm{~cm}^{-1}$ [30]. The stretching mode of the -OH bond was denoted by a peak at $3562 \mathrm{~cm}^{-1}$. The FTIR spectrum of conduit external surface showed peaks characteristic for chitosan, hydroxyapatite, lactic acid, and hyaluronic acid [8]. Deformation of peaks at 1647 and $1580 \mathrm{~cm}^{-1}$ suggested the formation of new interactions between chitosan chains and hydroxyapatite-derived moieties. Moreover, the conduit surface showed weak signals at $1735 \mathrm{~cm}^{-1}$, which might indicate the presence of lactate ions. Characteristic bands for hydroxyapatite moieties could be observed at $960 \mathrm{~cm}^{-1}$ due to the presence of symmetric stretching vibrations of $v_{1}\left(\mathrm{PO}_{4}{ }^{3-}\right)$.

Mean ultimate stress, mean ultimate strain, and Young's modulus were calculated from the initial length and thickness of implants. An example of the stress-strain curve is presented in Figure 5D. The ultimate stress is measured as force per sample initial crosssectional area at tensile failure, whereas the ultimate strain corresponds to the sample elongation achieved at the point of tensile failure divided by its initial length. Young's modulus refers to the ability of a sample to withstand changes in length subjected to lengthwise tension. The ultimate stress, ultimate strain, and Young's modulus of the $\mathrm{CH} / \mathrm{NGF}-\mu \mathrm{S} / \mathrm{PCL}$ conduit were equal to $1.57 \pm 0.50 \mathrm{MPa}, 0.68 \pm 0.22 \mathrm{~mm} / \mathrm{mm}$, and $1.85 \pm 0.21 \mathrm{MPa}$, respectively.

The literature states that the mechanical properties of implants intended for peripheral nerve tissue should be referred to those of native peripheral nerve tissue. For example, the ultimate stress, ultimate strain, and Young's modulus of acellular rat sciatic nerves are equal to $1.40 \pm 0.29 \mathrm{MPa}, 0.48 \pm 0.12 \mathrm{~mm} / \mathrm{mm}$, and $0.580 \pm 0.16 \mathrm{MPa}$, respectively [31]. On the basis of the obtained measurements, it can be concluded that the mechanical properties of the $\mathrm{CH} / \mathrm{NGF}-\mu \mathrm{S} / \mathrm{PCL}$ conduit are sufficient to fulfil the requirements of peripheral nerve tissue engineering. 
A

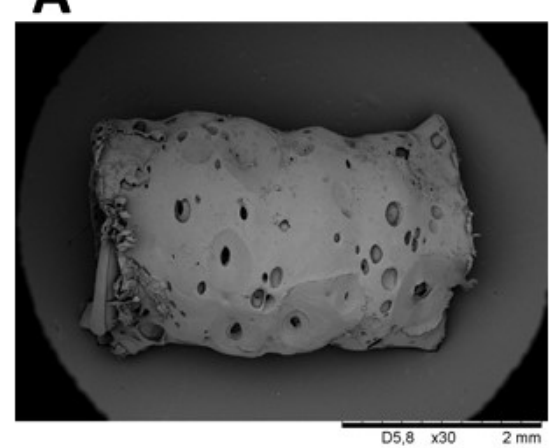

C
B

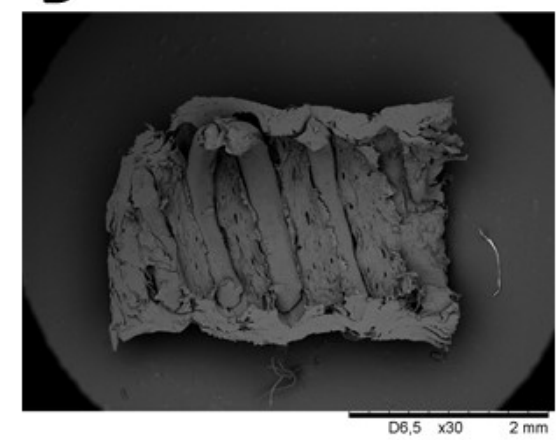

HA |V(O-H) overlapped | || || $1+\mathrm{H}_{2}, \mathrm{v}_{\mathrm{s}}(\mathrm{C}-\mathrm{O}-\mathrm{C})$ and
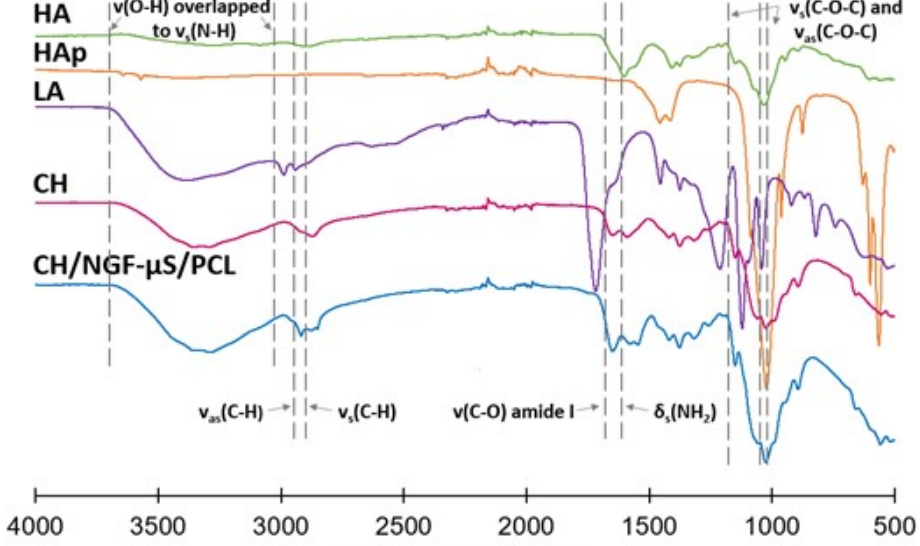

Wavenumber $\left[\mathrm{cm}^{-1}\right]$

D

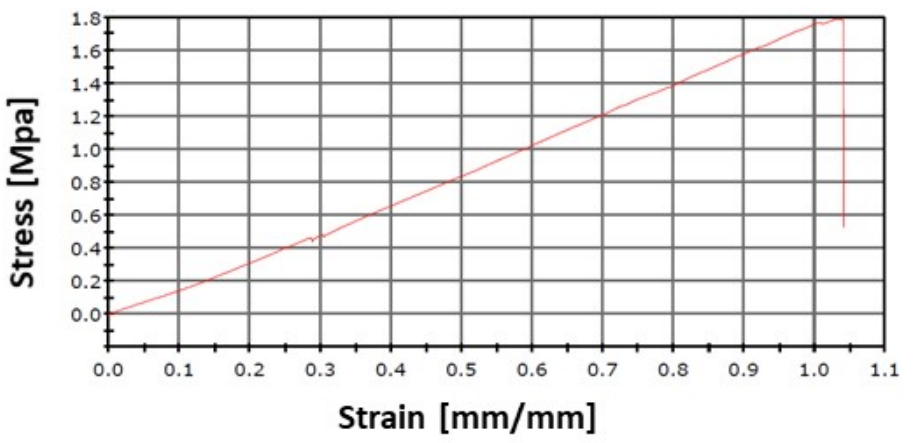

Figure 5. SEM images at $30 \times$ magnification of (A) longitudinal view and (B) inner sidewall view of $\mathrm{CH} / \mathrm{NGF}-\mu \mathrm{S} / \mathrm{PCL}$ conduit. (C) FTIR spectrum of outer side of external surface of CH/NGF- $\mu \mathrm{S} / \mathrm{PCL}$ conduit. (D) Example of stress-strain profile.

\subsection{Kinetics of In Vitro Biodegradation}

The obtained conduits undergo mass loss after 7 days up to 28 days of incubation in phosphate-buffered solution ( $\mathrm{pH}$ 7.4) with lysozyme at $37^{\circ} \mathrm{C}$ (Figure 6A). One-way ANOVA indicated significant differences in the case of mass change, $\mathrm{F}_{(4,20)}=8.664, p=0.0003$. Subsequent post hoc Tukey's test indicated that the sample at day 28 differed from samples at days $0(p<0.003), 1(p<0.002)$, and $7(p<0.002)$. The kinetics of conduit mass loss upon storage in phosphate-buffered solution (PBS, $\mathrm{pH} 7.4$ ) containing $1.5 \mathrm{mg} / \mathrm{mL}$ of lysozyme corresponds to that obtained in the literature [32]. Moreover, one-way ANOVA did not indicate significant changes in water content up to 28 days of conduit incubation, $\mathrm{F}_{(4,20)}=2.469, p=0.0779$ (Figure $6 \mathrm{~B}$ ). 
A

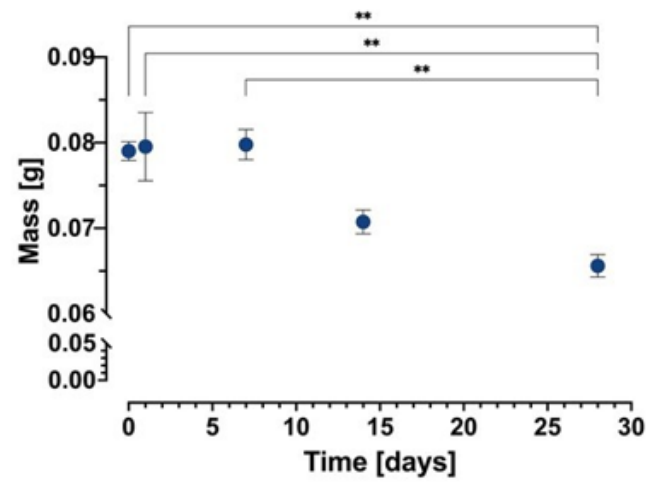

B

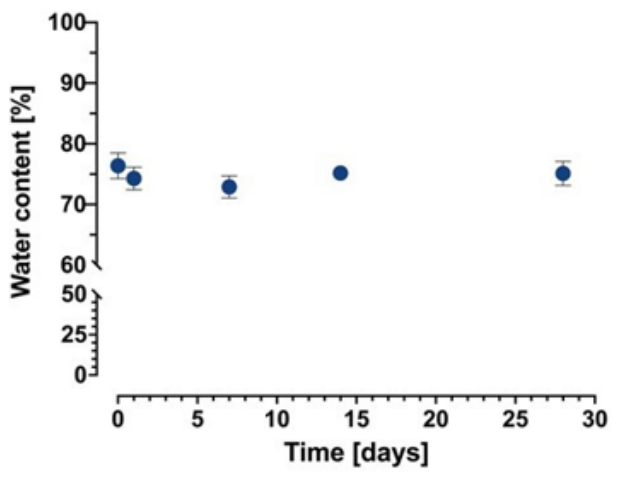

Figure 6. Change in (A) mass and (B) water content during incubation of $\mathrm{CH} / \mathrm{NGF}-\mu \mathrm{S} / \mathrm{PCL}$ conduits in phosphate-buffered solution ( $\mathrm{pH} 7.4$ ) with lysozyme at $37^{\circ} \mathrm{C}$ up to 28 days. Values with statistically significant differences are labeled by asterisks: ${ }^{* *} p<0.005$.

\subsection{Cell Activity and Morphology}

$\mathrm{CH} / \mathrm{NGF}-\mu \mathrm{S} / \mathrm{PCL}$ conduits were tested for their cytocompatibility toward the mHippoE18 cell line. Possible cytotoxicity was evaluated upon direct contact of the conduit with the cell monolayer after $24 \mathrm{~h}$ of incubation and expressed as the mean viability of cells $\pm \mathrm{SD}$ in relation to cells cultured in the presence of a commercially available reference biomaterial Safety-Lok ${ }^{\mathrm{TM}}$ blood collection set (BCS). The results were compared with those obtained for a conduit made of chitosan hydrogel deposit ( $\mathrm{CH}$ conduit). As shown in Figure 7, both tested conduits, similarly to the BCS reference material, had no cytotoxic activity toward mHippoE- 18 cells, and the viability exceeded $100 \%$ for $\mathrm{CH}$ and $\mathrm{CH} / \mathrm{NGF}-\mu \mathrm{S} / \mathrm{PCL}$ conduits: $107.3 \% \pm 7.8 \%$ and $105.6 \% \pm 6.6 \%$, respectively. These findings are in line with the cytocompatibility of chitosan/PCL-based biomaterials obtained by other researchers [33,34]. In the case of the obtained $\mathrm{CH} / \mathrm{NGF}-\mu \mathrm{S} / \mathrm{PCL}$ conduit, it was shown that this biomaterial candidate remains completely harmless (beyond $100 \%$ viability compared to control biomaterial) to more sensitive mHippoE-18 hippocampal cells. Moreover, one-way ANOVA indicated significant differences in the viability of mHippoE-18 cells, $\mathrm{F}_{(3,20)}=212.2, p<0.0001$, and subsequent post hoc Tukey's test indicated that only cells treated with $\mathrm{H}_{2} \mathrm{O}_{2}$ differed from samples BCS $(p<0.0001), \mathrm{CH}$ conduit $(p<0.0001)$, and CH/NGF- $\mu$ S/PCL conduits $(p<0.0001)$.

The influence of $\mathrm{CH} / \mathrm{NGF}-\mu \mathrm{S} / \mathrm{PCL}$ conduit on mHippoE-18 cell morphology and axon elongation was also tested. The cells maintained their regular morphology growing in the presence of both $\mathrm{CH}$ and $\mathrm{CH} / \mathrm{NGF}-\mu \mathrm{S} / \mathrm{PCL}$ conduits, as shown in the light microscope images (Figure 8(Bii, iii)), compared to cells propagated in the presence of commercially available control biomaterial-BCS (Figure 8(Bi)). Furthermore, a significant axon elongation was observed in the presence of $\mathrm{CH} / \mathrm{NGF}-\mu \mathrm{S} / \mathrm{PCL}(56.00 \pm 13.0 \mu \mathrm{m})$ and $\mathrm{CH}(45.4 \pm 13.8 \mu \mathrm{m})$ conduits, when compared to BCS reference polymer $(31.7 \pm 8.3 \mu \mathrm{m})$ (Figure $8 \mathrm{~A}$ ). Furthermore, the $\mathrm{CH} / \mathrm{NGF}-\mu \mathrm{S} / \mathrm{PCL}$ conduit was shown to induce the strongest axonal elongation; hippocampal cells in response to NGF-modified $\mathrm{CH} / \mathrm{PCL}$ biomaterial produced significantly longer axons when compared to $\mathrm{CH}$ and BSC biomaterials. Moreover, it was shown that $\mathrm{CH} / \mathrm{NGF}-\mu \mathrm{S} / \mathrm{PCL}$ conduit is not only cytocompatible, but also supports the increase in axonal length due to the presence of NGF.

The obtained results give strong evidence that the process of conduit production did not affect the biological activity of this neurotrophic polypeptide manifested by axonal elongation observed in the presented study and in the literature [35-37]. 


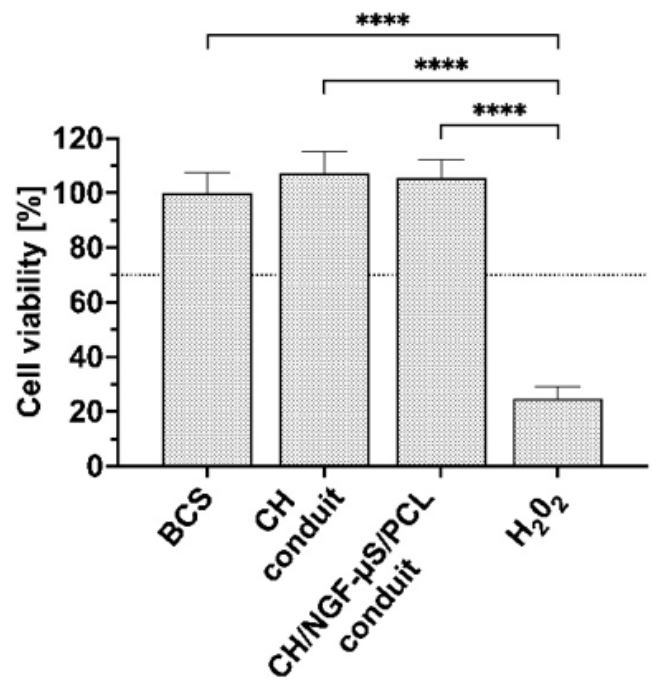

Figure 7. The viability of mHippoE-18 cells exposed for $24 \mathrm{~h}$ to $\mathrm{CH}$ and $\mathrm{CH} / \mathrm{NGF}-\mu \mathrm{S} / \mathrm{PCL}$ conduits. Data are shown as the mean viability \pm standard deviation $(n=6)$ compared to cells grown in the presence of BCS reference biomaterial $(n=6)$. Values with statistically significant differences are labeled by brackets and asterisks: ${ }^{* * * *} p<0.0001$. Data were compared using an ordinary one-way ANOVA followed by Tukey's multiple comparisons.

A

B
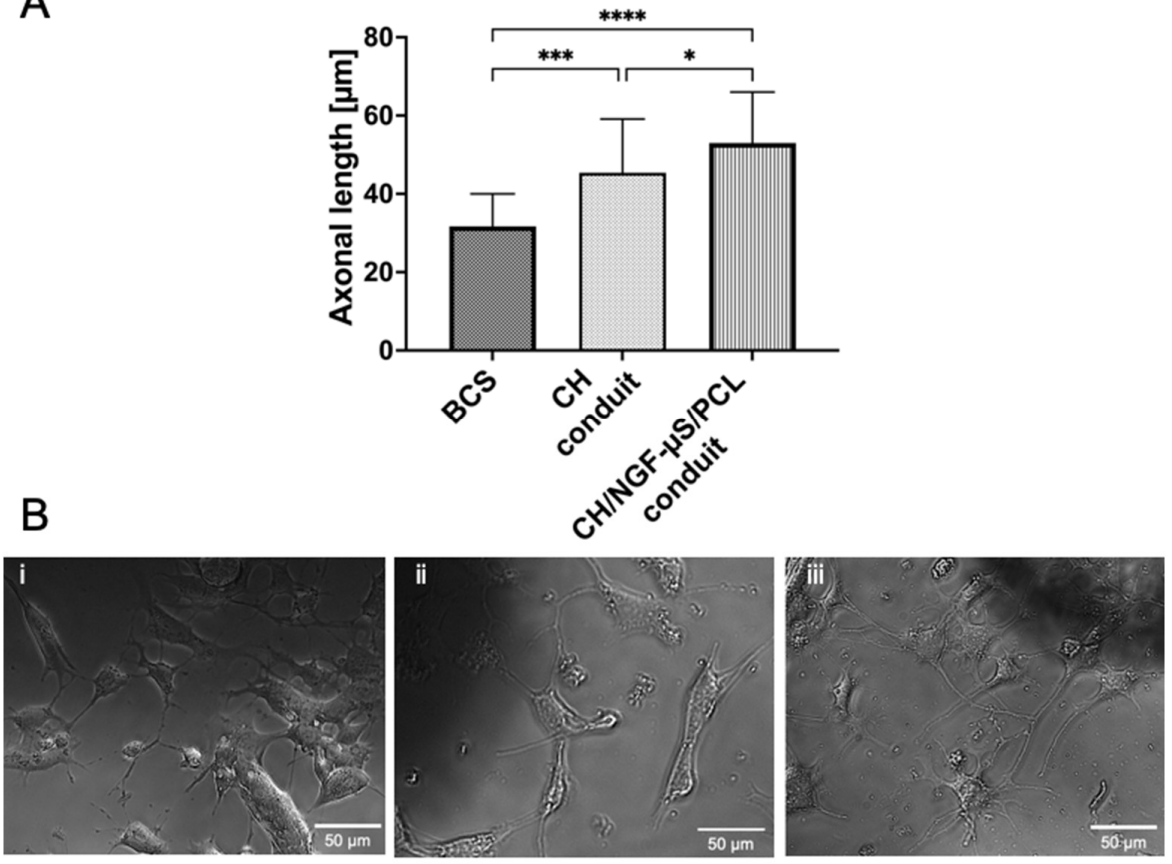

Figure 8. The influence of $\mathrm{CH}$ and $\mathrm{CH} / \mathrm{NGF}-\mu \mathrm{S} / \mathrm{PCL}$ conduits on mHippoE-18 cells regarding their ability to stimulate axon elongation (A) and morphology (B) evaluated by light microscopy: mHippoE-18 cells grown in the presence of commercially available biomaterial BCS (i), $\mathrm{CH}$ conduit (ii), and CH/NGF- $\mu \mathrm{S} / \mathrm{PCL}$ conduit (iii). Conduits are visible as darker areas in the pictures. Values with statistically significant differences are labeled by brackets and asterisks as follows: ${ }^{*} p<0.05$, $* * * p<0.001,{ }^{* * * *} p<0.0001$. Data were compared using an ordinary one-way ANOVA followed by Tukey's multiple comparisons.

To address the question whether the obtained scaffolds support cell proliferation, the total DNA content in cells exposed to both $\mathrm{CH}$ and $\mathrm{CH} / \mathrm{NGF}-\mu S / \mathrm{PCL}$ conduits or maintained in the presence of commercially available biomaterial (BCS) was measured. Oneway ANOVA did not indicate significant changes in the proliferation rate of mHippoE-18 in 
the presence of tested conduits and control biomaterial $\mathrm{F}_{(2,6)}=0.8760, p=0.4637$ (Figure 9). The lack of proliferation might be explained by the observed changes in morphology, which was targeted on adhesion and axonal elongation, rather than cell expansion.

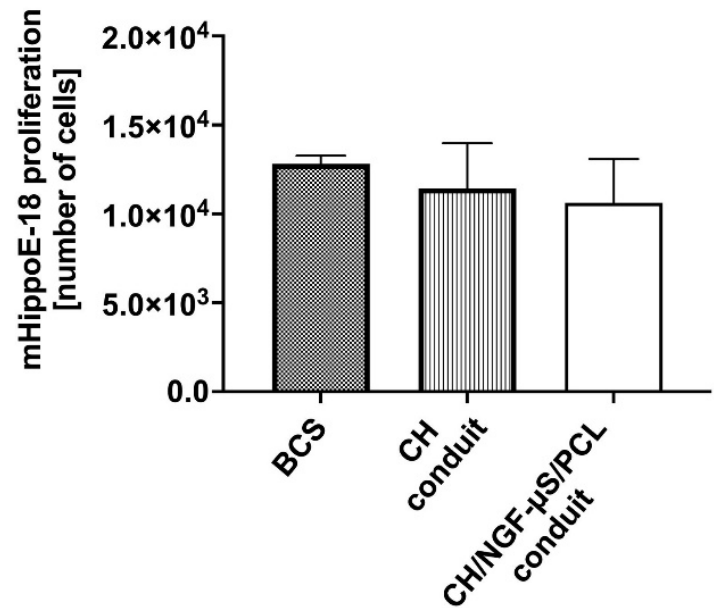

Figure 9. Proliferation of mHippoE-18 cells in response to $\mathrm{CH}$ and $\mathrm{CH} / \mathrm{NGF}-\mu \mathrm{S} / \mathrm{PCL}$ conduits in comparison to proliferation rate in the presence of the reference material (BCS). Data are shown as a mean from three repeats with error bars that indicate standard deviation. Data were compared using an ordinary one-way ANOVA followed by Tukey's multiple comparisons.

\subsection{Conduit-Mediated NF- $K B$ Activation}

Using the THP1-Blue ${ }^{\mathrm{TM}} \mathrm{NF}-\mathrm{kB}$ reporter cell line, it was shown that $\mathrm{CH} / \mathrm{NGF}-\mu \mathrm{S} / \mathrm{PCL}$ conduit and the commercial reference biomaterial intended for contact with body fluids did not induce NF- $\mathrm{KB}$ activation higher than that induced by a critical level of lipopolysaccharide (LPS, $0.25 \mathrm{IU} / \mathrm{mL}$ ) allowed to remain in such biomaterials (Figure 10).

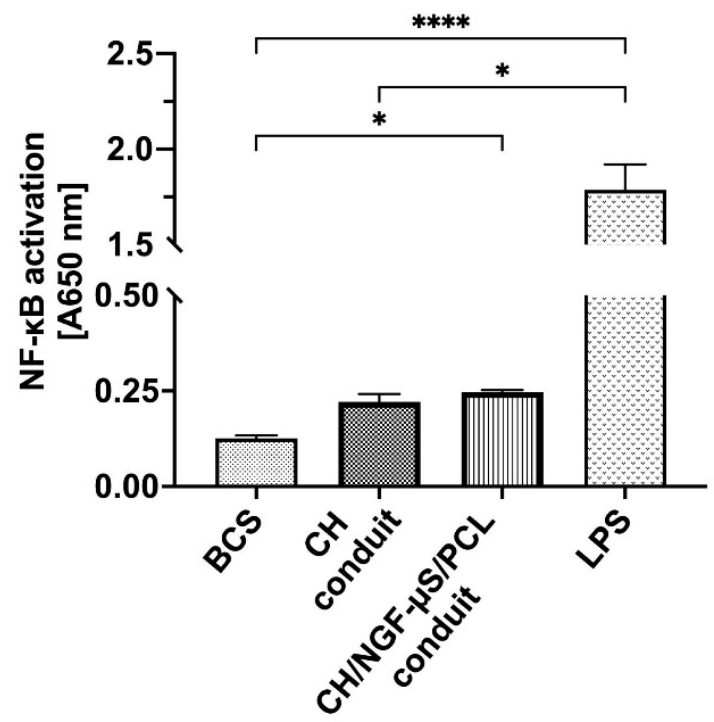

Figure 10. The NF- $\mathrm{kB}$ induction in THP1-Blue ${ }^{\mathrm{TM}}$ human monocytes exposed to $\mathrm{CH}$ or $\mathrm{CH} / \mathrm{NGF}-$ $\mu \mathrm{S} / \mathrm{PCL}$ conduits, BCS reference biomaterial (negative control), or E. coli lipopolysaccharide (LPS) at 0.25 IU (positive control). Data are shown as a mean from four repeats with error bars that indicate standard deviation. Values with statistically significant differences are labeled by brackets and asterisks as follows: ${ }^{*} p<0.05,{ }^{* * * *} p<0.0001$. Data were compared using a regular one-way ANOVA followed by Tukey's multiple comparisons. 
The LPS-induced activation was significantly higher when compared with BCS-treated cells $(p<0.0001)$ and $\mathrm{CH}$ conduit $(p<0.005)$. Interestingly, the $\mathrm{CH} / \mathrm{NGF}-\mu \mathrm{S} / \mathrm{PCL}$ conduit induced monocyte activation when compared to BCS $(p<0.005)$.

Implants with possible application in nerve regeneration or other conduits having contact with blood, tissues, or body fluids should remain noncytotoxic, while they also cannot contain contaminants that may induce pathological inflammation. Bacterial endotoxins (lipopolysaccharides) are microbial components inducing strong inflammation which, in the first stages, target innate immunity cells such as monocytes. Monocytes using Toll-like receptor 4 (TLR-4) recognize and rapidly react to bacterial LPS, and consequently strongly induce nuclear transcription factor (NF-kB) [38]. LPS-induced inflammation has pathological consequences, e.g., in intestinal and endothelial dysbiosis [39] or during sepsis [40]. However, as shown recently, mild activation of these cells is crucial for proper tissue regeneration. The reason for this diverse role in repair is unclear, but inflammation, specifically monocyte activation, likely plays a key role. Monocytes and monocyte-derived macrophages promote the repair of injured sites, including nerve tissue, possibly by regulating transitions through phases of the healing response [41].

In the presented work, it was shown that $\mathrm{CH} / \mathrm{NGF}-\mu \mathrm{S} / \mathrm{PCL}$, similarly to $\mathrm{CH}$ conduit, and the BSC reference material did not contain endotoxin in concentration exceeding the critical level for biomaterials having contact with body fluids (ISO 10993-5:2009). On the other hand, the CH/NGF- $\mu S$ /PCL conduit exclusively induced low, albeit statistically significant, activation of monocytes, when compared to the reference biomaterial. The monocyte stimulation, in the milieu of additional external signals (such as cytokines, chemokines, and alarmins) transform into macrophages which contribute to all phases of repair: by promoting inflammation, removing injured cells, depositing ECM, stimulating cell proliferation, and releasing anti-inflammatory cytokines that stop the inflammation [41,42]. NGF-mediated monocyte activation was shown to be implicated in spinal cord tissue regeneration [41]. When strongly activated, however, monocytes and monocyte-derived macrophages may interrupt different phases of repair and lead to chronic inflammation and dysfunctional wound healing [43]. Pioneering and recent findings have shown that human monocyte-derived macrophages respond to NGF, and this effect is corelated with morphological and secretory activity, favoring the healing process [44,45].

\section{Materials and Methods}

\subsection{Materials}

Chitosan (CH, type 85/500) was purchased from Heppe Medical Chitosan GmbH (Halle, Germany). Its degree of deacetylation (DD), viscosity ( $\mu, 1 \%$ in $1 \%$ acetic acid, $20^{\circ} \mathrm{C}$ ), and viscosity-average molecular weight $(\mathrm{Mv})$ were respectively $82.6-87.5 \%, 351-750 \mathrm{mPa} \cdot \mathrm{s}$, and $472 \mathrm{kDa}$. Polycaprolactone (PCL, mean Mn 80,000 mol/wg), dichloromethane (DCM), lactic acid (LA), poly(vinyl alcohol) (PVA), and hydroxyapatite (HAp, nanopowder, $<200 \mathrm{~nm}$ particle size) were purchased from Merck KGaA (Darmstadt, Germany). Sodium hyaluronate of average molecular weight 2000-2200 kDa was purchased from Contipro (Dolní Dobrouč, Czech Republic). Poly(lactide-co-glycolide) (PLGA Resomer ${ }^{\circledR}$ RG 503 H, acid-terminated, lactide/glycolide 50:50) was obtained from Merck KGaA (Darmstadt, Germany). Nerve growth factor (NGF, recombinant mouse protein with an initial Met at the N-terminus) was purchased from Life Technologies (Waltham, MA, USA).

\subsection{Printing of Polycaprolactone Filament}

A four-axis CNC milling machine (Computerized Numerical Control, Shanding UMay Cnc Technology Co., Ltd., Jinan, China) was adapted for working in the vertical plane [8]. The device was described earlier in a patent application to the Patent Office of the Republic of Poland: P. 428594 (2019). The apparatus was equipped with a custommade 3D print head. The head was built from the following elements: two aluminum blocks, two collaterally connected ceramic heaters of a diameter $6 \mathrm{~mm}$ (set at $6 \mathrm{~W}$ each), a $0.4 \mathrm{~mm}$ diameter nozzle, a thermal barrier with an internal polytetrafluoroethylene 
layer (connecting aluminum blocks and serving as a casing for the melted filament), and a thermocouple coupled with a PID (proportional-integral-derivative) transmitting G8 controller for keeping a constant temperature of $60^{\circ} \mathrm{C}$. The print head was also equipped with a piston. The piston was made of a $2 \mathrm{~mm}$ diameter stainless-steel rod set in motion by the Z-axis motor of the milling machine.

The polycaprolactone filament was produced using a Felfil Evo extruder (Felfil Evo Filament Extruder, Turin, Italy). The extruder operating parameters were set to produce a PCL filament with a diameter of approximately $1.4 \mathrm{~mm}$.

The thermoplastic printing material in the form of the filament was placed in the feeder of a 3D print head. A cylindrical rod made of material consistent with PN-EN ISO 14343 (PN-EN 12072): W 199 LSi AWS A5.9: ER 308LSi was used as a build plate. The diameter of the rod can be adjusted to the desired implant dimensions. The presented studies were conducted for a rod with a diameter of $2 \mathrm{~mm}$. Then, the cylindrical rod was set in motion by the A-axis motor of the milling machine. A G-code used to print polymer skeletons was prepared manually during optimization studies and implemented in Mach3 CNC Controller software (version R3.041, ArtSoft Inc., Livermore Falls, ME, USA).

The CNC milling machine was also equipped with a cylindrical stainless-steel reactor for conducing electrophoretic deposition. The inner diameter of the reactor can be adjusted to the desired implant dimensions. The presented studies were conducted using the reactor with an inner diameter of $22 \mathrm{~mm}$.

\subsection{Preparation and Characterization of Microspheres}

Microspheres were prepared using the standard water/oil/water (W/O/W) double emulsion technique with solvent evaporation [25]. Three concentrations of PLGA solution in dichloromethane were prepared: 20\%, 25\%, and $40 \%$. Then, $0.08 \mathrm{~mL}$ of an aqueous protein solution dissolved in PBS containing $0.1 \%(w / v)$ BSA alone or in combination with $0.025 \mathrm{mg}$ of NGF was added to PLGA solution. The mixture was homogenized for $60 \mathrm{~s}$ using an ultrasonic homogenizer (Sonoplus HD 2070 homogenizer; Bandelin Electronics $\mathrm{GmbH} \& \mathrm{Co}$. KG, ) operating at $10 \%$ power and a cycle count of six. Then, the homogenized mixture was poured to $25 \mathrm{~mL}$ of $1 \mathrm{wt}$ \% PVA aqueous solution and homogenized for $1 \mathrm{~min}$ using a homogenizer set at power $=50 \%$ and number of cycles $=6$. Finally, the volume was increased to $25 \mathrm{~mL}$ by adding $0.1 \mathrm{wt}$ \% PVA aqueous solution and homogenized for another $1 \mathrm{~min}$ using a homogenizer set at power $=50 \%$ and number of cycles $=6$ for $1 \mathrm{~min}$. Then, the entire mixture was stirred for $1 \mathrm{~h}$ on a magnetic stirrer at room temperature. After complete solvent evaporation, the microspheres were centrifuged ( $2500 \mathrm{rpm}$ for $3 \mathrm{~min}$ at room temperature) and washed twice by centrifugation ( $2500 \mathrm{rpm} 3 \mathrm{~min}$ at room temperature) in $50 \mathrm{~mL}$ of sterile deionized water.

\subsection{Polycaprolactone Filament Surface Modification}

PCL helices obtained for G-code: F8500 Z-240 A17600 Y-132 Z-8 were placed in a solution of $0.2 \%, 0.4 \%$, or $0.6 \%$ dopamine hydrochloride in Tris buffer $(0.183 \mathrm{~g}$ Tris in $150 \mathrm{~mL}$ deionized water with $\mathrm{pH}$ adjusted to 8.5 using $0.5 \mathrm{mM}$ hydrochloric acid) [46]. The solutions were subjected to gentle stirring without light for $24 \mathrm{~h}$. Afterward, the PCL helices were removed from the buffer solution and rinsed by immersion in deionized water three times. Then, the PCL helices were placed in a solution containing $2.34 \%$ of microspheres and subjected to gentle stirring for $2 \mathrm{~h}$. For the PCL helix modified in $0.4 \%$ dopamine hydrochloride, three concentrations of microspheres were applied: $1.19 \%, 1.5 \%$, and $2.34 \%$.

\subsection{Conduit Manufacturing}

The build plate with PCL helix was placed in a handle of the CNC milling machine described above and aligned straight along the $Y$-axis. Then, the reactor for conducting electrophoretic deposition containing the solution was installed. The chitosan solution concentration was chosen according to previous studies [47]. Briefly, the solution was prepared by dissolving $10 \mathrm{mg}$ of hyaluronic acid in $100 \mathrm{~mL}$ of $2.5 \%(w / v)$ lactic acid. Then, 
$1 \mathrm{~g}$ of chitosan and $0.09 \mathrm{~g}$ of hydroxyapatite were added to the solution. The obtained solution was stirred (under slow rotations) until complete dissolution for $24 \mathrm{~h}$. After dissolution, $16 \mathrm{~mL}$ of the solution was poured into the cylindrical reactor with an internal diameter of $18 \mathrm{~mm}$. Then, the electrophoretic deposition process was conducted for $15 \mathrm{~min}$ at room temperature at $12 \mathrm{~V}$. After the set time, the obtained chitosan/polycaprolactone conduit of average length $40.0 \pm 0.2 \mathrm{~mm}$ was removed automatically from the reactor and taken manually off from the electrode.

\subsection{Structural Characterization}

\subsubsection{Scanning Electron Microscopy}

Dry implants were cut into specimens of length $5 \pm 0.2 \mathrm{~mm}$ for further examination. Scanning electron microscopy photographs of gold-coated deposits were taken with a Hitachi TM-1000 microscope (Hitachi Ltd., Tokyo, Japan).

\subsubsection{Fourier Transform Infrared Spectroscopy}

The fabricated conduits were dried at $37^{\circ} \mathrm{C}$ for 5 days. Samples were examined using a Nicolet ${ }^{\mathrm{TM}}$ iS50 FTIR spectrophotometer (Thermo Fisher Scientific, Waltham, MA, USA) with an ATR monolithic diamond crystal mounted. Spectra were recorded in the range of $0-4500 \mathrm{~cm}^{-1}$.

\subsubsection{Mechanical Testing}

Mechanical properties of conduits were investigated by an Instron 3345 apparatus (Instron, USA). The initial length of specimens was $40 \pm 1 \mathrm{~mm}$. The ends of samples were inserted on two $5 \mathrm{~mm}$ cylindrical internal supports in order to prevent their deformation. Then, the conduit ends were fixed in specially designed clamps. Initially, the distance between the clamps was set to $20 \mathrm{~mm}$. Implants were tested at a strain rate of $3 \mathrm{~mm} / \mathrm{min}$ at room temperature. Each sample was stretched to the complete tensile failure. A mean value of at least three different measurements was determined, and a standard deviation was calculated.

\subsubsection{Water Content}

In order to determine the water content, the conduits were divided into two groups: hydrated and dry. The mass of hydrated specimens was measured just after their preparation. To determine the mass of dry specimens, structures were placed at $70 \pm 0.1{ }^{\circ} \mathrm{C}$ for $24 \mathrm{~h}$. The mass of hydrated and dry conduits was determined after subtracting the mass of the PCL helix. The mean value of three different measurements for both measurements was determined, and the standard deviation was calculated. The water content was determined using the following equation:

$$
X=\frac{m_{h}-m_{d}}{m_{h}} \cdot 100 \%,
$$

where $X$ is the water content $(\%), m_{h}$ is the mass of the chitosan hydrogel deposit $(\mathrm{g})$, and $m_{d}$ is the mass of the dry chitosan deposit (g).

\subsection{Protein Controlled Release Studies}

In order to assess NGF release kinetics from NGF- $\mu \mathrm{S} / \mathrm{PCL}$ helix, $1 \mathrm{~cm}$ helices were placed in a solution of phosphate-buffered saline ( $\mathrm{pH} 7.4)$, bovine serum albumin, and an antibiotic (streptomycin and penicillin). The solutions were subjected to gentle shaking at $37^{\circ} \mathrm{C}$. Released neurotrophic factor was collected by centrifugation of the microparticles at $1000 \mathrm{rpm}$ at room temperature and resuspending in PBS at the following timepoints for quantification via ELISA: 1, 3, 7, and 14 days. The ELISA was carried out as per manufacturer's instructions (Wuhan Fine Biotech Co., Ltd., Wuhan, China) to determine the cumulative release kinetics of NGF from PCL helices. 


\subsection{Biodegradation Studies}

The in vitro degradation was performed in $20 \mathrm{~mL}$ of phosphate-buffered solution (PBS, pH 7.4, Merck KGaA, Germany) and in $20 \mathrm{~mL}$ of phosphate-buffered solution (PBS, $\mathrm{pH} 7.4$ ) containing $1.5 \mathrm{mg} / \mathrm{mL}$ of lysozyme (human lysozyme, Merck KGaA, Germany). The lysozyme dose was selected on the basis of its physiological concentration in human serum [48]. Briefly, tubular conduits (prepared according to the procedure described in previous section) were incubated in the solution at $37^{\circ} \mathrm{C}$ for the period of $1,7,14$, and 28 days. The lysozyme solution was refilled three times per week to maintain enzyme activity. After $1,7,14$, and 28 days samples were removed from the medium, dried at $70{ }^{\circ} \mathrm{C}$ for $48 \mathrm{~h}$, and weighed. A mean value of at least four different measurements (i.e., four independent samples) was determined, and a standard deviation was calculated.

\subsection{Biological Properties of the Conduit}

\subsubsection{Cell Culture and Preparation for the Biological Assays}

The hippocampal mouse cells (mHippoE-18, CELLutions Biosystems, Ontario, Canada) were routinely maintained in DMEM high-glucose culture medium (Sigma-Aldrich, Missouri, MO, USA) without sodium pyruvate. The THP1-Blue ${ }^{\mathrm{TM}} \mathrm{NF}-\mathrm{kB}$ cells derived from the human monocytic THP-1 cell line (Invivogen, Toulouse, France) were maintained in RPMI 1640 medium (Cytogen, Zgierz, Poland). Media for both cell lines were supplemented with $10 \%$ fetal bovine serum (Biowest, Nuaille, France), $100 \mathrm{U} / \mathrm{mL}$ penicillin, and $100 \mu \mathrm{g} / \mathrm{mL}$ streptomycin (Penicillin-Streptomycin Solution ATCC ${ }^{\circledR}$ ). In addition, the medium for THP1Blue $^{\text {TM }}$ NF- $\kappa$ B was supplemented with $100 \mu \mathrm{g} / \mathrm{mL}$ normocin (InvivoGen, San Diego, CA, USA), and $10 \mu \mathrm{g} / \mathrm{mL}$ blastocidin (InvivoGen, USA). The mHippoE-18 cells were trypsinized (Trypsin-EDTA Solution, ATCC ${ }^{\circledR}$ ) twice a week, seeded at a density of $5 \times 10^{5}$ cells per T25 cell culture flask, and incubated at $37{ }^{\circ} \mathrm{C}$ and $5 \% \mathrm{CO}_{2}$ to obtain a confluent monolayer. The THP1-Blue ${ }^{\mathrm{TM}} \mathrm{NF}-\mathrm{\kappa B}$ cells were also incubated at $37^{\circ} \mathrm{C}$ in a humidified incubator with $5 \%$ $\mathrm{CO}_{2}$ and passaged every 3 days to maintain density $<2 \times 10^{6}$ cells $/ \mathrm{mL}$.

\subsubsection{Direct Contact Cytotoxicity Assay}

The $\mathrm{CH}$ and $\mathrm{CH} / \mathrm{NGF}-\mu \mathrm{S} / \mathrm{PCL}$ conduits were tested for cytotoxic properties upon direct contact with mHippoE-18 embryonic hippocampal cells, as described previously [26]. Briefly, the hippocampal cells were seeded in the 96-well plate at a density of $2 \times 10^{4}$ cells /well and incubated for $24 \mathrm{~h}$. Tested implants were cut into fragments constituting $1 / 10$ of the well surface and placed carefully on the cell monolayer. After $24 \mathrm{~h}$ of incubation, the MTT reduction assay was used to determine the viability of the cells. The viability was calculated in comparison to cells grown in the presence of the commercially available biomaterial (BCS, Safety-Lok ${ }^{\mathrm{TM}}$ blood collection set, BD, Franklin Lakes, NJ, USA), which served as a positive control of viability (100\%). Hydrogen peroxide 3\% (Sigma-Aldrich, Missouri, MO, USA) was used as a negative control of viability.

\subsubsection{Cell Proliferation}

To determine the influence of $\mathrm{CH} / \mathrm{NGF}-\mu \mathrm{S} / \mathrm{PCL}$ conduit on mHippoE-18 cell proliferation, we performed an assay where $0.2 \mathrm{~mL}$ of hippocampal cell suspension $\left(5 \times 10^{4}\right.$ cells $\left./ \mathrm{mL}\right)$ was seeded in a 96-well tissue culture plate (Corning, Wilmington, NC, USA); then, after $24 \mathrm{~h}$ of incubation, the conduit fragments constituting 1/10 of the well surface were placed carefully on the cell monolayer. After another $24 \mathrm{~h}$ of incubation, DNA content was measured using a CyQUANT ${ }^{\circledR}$ Cell Proliferation Assay Kit (Thermo Fisher Scientific, Waltham, Massachusetts). The wells with samples were washed with PBS and then frozen at $-80^{\circ} \mathrm{C}$. Next the plate was thawed at room temperature, and samples were lysed in buffer containing the CyQuant-GR dye, which bound to cellular nucleic acids. Fluorescence was measured using SpectraMax ${ }^{\circledR}$ i3x Multi-Mode Microplate Reader (Molecular Devices, San Jose, CA, USA) at $E_{m}=520 \mathrm{~nm}$ and $E_{x}=480 \mathrm{~nm}$. The commercially available biomaterial Safety-Lok ${ }^{\mathrm{TM}}$ blood collection (BCS) served as a negative control. 


\subsubsection{Cell Morphology}

To evaluate the influence of $\mathrm{CH} / \mathrm{NGF}-\mu \mathrm{S} / \mathrm{PCL}$ conduit on mHippoE-18 cells, we performed an assay where $0.2 \mathrm{~mL}$ of hippocampal cell suspension $\left(5 \times 10^{4}\right.$ cells $\left./ \mathrm{mL}\right)$ was added on the biomaterial placed in 96-well tissue culture plates (Corning, Wilmington, NC, USA). After $48 \mathrm{~h}$ incubation, cells propagating near biomaterial were analyzed, and their axonal length was measured with the use of inverted microscope (IX50 microscope with UC90 camera, Olympus, Tokyo, Japan). To evaluate the average axonal length, microscopic analysis of at least 100 cells was performed using cellSens software (cellSens Standard 2.3, Olympus, Tokyo, Japan).

\subsubsection{Quantification of NF- $\mathrm{kB}$ Induction}

To address the question whether the obtained conduits activate monocytes, we used the THP1-Blue ${ }^{\mathrm{TM}} \mathrm{NF}-\mathrm{kB}$ reporter cell line, which enables to quantify the induction of NF- $\mathrm{kB}$ transcription factor in monocytes. The test was performed according to the procedure described previously [49]. Briefly, the THP1-Blue ${ }^{\mathrm{TM}} \mathrm{NF}-\mathrm{kB}$ cells were seeded in 24-well plates at a density of $1 \times 10^{6}$ cells $/ \mathrm{mL}$; then, the conduits, cut into fragments constituting $1 / 10$ of the well surface, were introduced to each well and incubated for $24 \mathrm{~h}$. Next, $20 \mu \mathrm{L}$ of supernatants from monocyte cultures were added to $200 \mu \mathrm{L}$ of Quanti-Blue ${ }^{\mathrm{TM}}$ reagent, and the quantification of alkaline phosphatase, as a marker of cell activation (inflammatory response), was measured at $650 \mathrm{~nm}$. The following controls were included: untreated monocyte cultures served as a negative control (cRMPI) and cultures treated with Escherichia coli (E. coli) lipopolysaccharide (LPS) (Sigma-Aldrich, USA) served as a positive control. Furthermore, the commercially available biomaterial Safety-Lok ${ }^{\mathrm{TM}}$ blood collection (BCS) served as a reference polymer. Experiments were independently repeated three times, and at least four repeats were included each time.

\subsection{Statistical Analysis and Graphs}

The results were subjected to statistical analysis with the use of GraphPad Prism version 9.0.0 on macOS (GraphPad Software, San Diego, CA, USA). Following the confirmation of data normality, the statistical significance of differences was evaluated in ANOVA test, and, for significant comparisons, further analysis was performed using the Tukey's multiple comparisons test. The differences were considered significant for a $p$-value $<0.05$.

\section{Conclusions}

A new approach for the incorporation of biologically active agent-loaded microspheres into the structure of chitosan/polycaprolactone conduits was described. Internal PCL helical thread was used to mechanically stabilize the conduit and provide the support for microspheres releasing the biologically active substances. The chitosan hydrogel tube produced by electrodeposition is perfectly suited for application as a nerve guidance conduit due to high water content and softness, mimicking the surrounding soft tissue. Upon incorporation of chitosan deposit with PCL helix, the structure provides space and environment for regrowing nerves and accumulation of signaling molecules, preventing infiltration with inflammatory cells and formation of fibrous tissue. The obtained results indicate that the developed strategy enables a spatiotemporal controlled release of nerve growth factors as the helix dimensions and geometry can be customized.

The structural properties of implants during incubation in phosphate-buffered solution ( $\mathrm{pH}$ 7.4) did not change significantly up to 28 days at $37^{\circ} \mathrm{C}$. Furthermore, implants manufactured by our technology are cytocompatible with neuronal cells, stimulate axonal growth of hippocampal cells due to controlled release of NGF, and activate monocytes via NF- $\mathrm{kB}$ transcription factor. These complex in vitro results give us a strong argument for further examination of the implants in an appropriate in vivo animal model. As peripheral nerve injuries represent a significant problem to be solved, the developed biologically active conduits contribute to the state of the art, providing solutions for conduit manufac- 
turing and the release of biologically active molecules required for efficient regrowth of the discontinued nerves.

\section{Patents}

A patent application was sent to the Patent Office of the Republic of Poland: P. 438938 (2021): A method of producing hybrid implants with a cylindrical shape for the controlled release of active substances.

Author Contributions: Conceptualization, K.N.; methodology, K.N., M.K., K.R., R.W., J.G., M.W., A.B. and S.M.; software, A.B. and M.W.; formal analysis, K.N.; investigation, K.N., M.K., K.R., J.G., M.W., A.B. and S.M.; resources, K.N.; data curation, M.K., M.W. and A.B.; writing-original draft preparation, K.N. and K.R.; writing-review and editing, K.N., K.R., M.K., J.G., M.W., A.B., S.M. and R.W.; visualization, K.N., M.K. and A.B.; supervision, K.N. and K.R.; project administration, K.N.; funding acquisition, K.N. All authors read and agreed to the published version of the manuscript.

Funding: This research was funded by the National Center for Research and Development, Poland, grant number LIDER/18/0116/L-10/18/NCBR/2019.

Institutional Review Board Statement: Not applicable.

Informed Consent Statement: Not applicable.

Data Availability Statement: The data presented in this study are available on request from the corresponding author.

Conflicts of Interest: The authors declare no conflict of interest.

\section{References}

1. Alvites, R.; Caseiro, A.R.; Pedrosa, S.S.; Branquinho, M.V.; Ronchi, G.; Geuna, S.; Varejão, A.S.; Maurício, A.C. Peripheral nerve injury and axonotmesis: State of the art and recent advances. Cogent Med. 2018, 5, 1466404. [CrossRef]

2. Belzberg, A.J. Peripheral Nerve Injury. In Current Therapy in Neurologic Disease, 7th ed.; Johnson, R.T., Griffin, J.W., McArthur, J.C., Eds.; Mosby: Philadelphia, PA, USA, 2006; pp. 244-253.

3. Stoll, G.; Müller, H.W. Nerve Injury, Axonal Degeneration and Neural Regeneration: Basic Insights. Brain Pathol. 1999, 9, 313-325. [CrossRef] [PubMed]

4. Gaudet, A.D.; Popovich, P.G.; Ramer, M.S. Wallerian degeneration: Gaining perspective on inflammatory events after peripheral nerve injury. J. Neuroinflamm. 2011, 8, 110. [CrossRef] [PubMed]

5. Geissler, J.; Stevanovic, M. Management of large peripheral nerve defects with autografting. Injury 2019, 50, S64-S67. [CrossRef]

6. Lin, M.Y.; Manzano, G.; Gupta, R. Nerve Allografts and Conduits in Peripheral Nerve Repair. Hand Clin. 2013, 29, 331-348. [CrossRef] [PubMed]

7. Kvist, M.; Sondell, M.; Kanje, M.; Dahlin, L.B. Regeneration in, and properties of, extracted peripheral nerve allografts and xenografts. J. Plast. Surg. Hand Surg. 2011, 45, 122-128. [CrossRef]

8. Nawrotek, K.; Mąkiewicz, M.; Zawadzki, D. Fabrication and Characterization of Polycaprolactone/Chitosan-Hydroxyapatite Hybrid Implants for Peripheral Nerve Regeneration. Polymers 2021, 13, 775. [CrossRef]

9. Jiang, X.; Lim, S.H.; Mao, H.-Q.; Chew, S.Y. Current applications and future perspectives of artificial nerve conduits. Exp. Neurol. 2010, 223, 86-101. [CrossRef]

10. Sun, B.; Zhou, Z.; Wu, T.; Chen, W.; Li, D.; Zheng, H.; El-Hamshary, H.; Al-Deyab, S.S.; Mo, X.; Yu, Y. Development of Nanofiber Sponges-Containing Nerve Guidance Conduit for Peripheral Nerve Regeneration in Vivo. ACS Appl. Mater. Interfaces 2017, 9 , 26684-26696. [CrossRef]

11. Du, J.; Jia, X. Engineering nerve guidance conduits with three-dimenisonal bioprinting technology for long gap peripheral nerve regeneration. Neural Regen. Res. 2019, 14, 2073-2074.

12. Song, S.; Wang, X.; Wang, T.; Yu, Q.; Hou, Z.; Zhu, Z.; Li, R. Additive Manufacturing of Nerve Guidance Conduits for Regeneration of Injured Peripheral Nerves. Front. Bioeng. Biotechnol. 2020, 8, 1141. [CrossRef]

13. Novajra, G.; Baino, F.; Raimondo, S.; Loustea, J.; Milanese, D.; Vitale-Brovarone, C. Chapter 18 Bioactive Glasses for Nerve Regeneration. In Bioactive Glasses: Fundamentals, Technology and Applications; The Royal Society of Chemistry: London, UK, 2017; pp. 420-441.

14. Ciardelli, G.; Chiono, V. Materials for Peripheral Nerve Regeneration. Macromol. Biosci. 2006, 6, 13-26. [CrossRef] [PubMed]

15. Vijayavenkataraman, S. Nerve guide conduits for peripheral nerve injury repair: A review on design, materials and fabrication methods. Acta Biomater. 2020, 106, 54-69. [CrossRef] [PubMed]

16. Gu, X.; Ding, F.; Yang, Y.; Liu, J. Construction of tissue engineered nerve grafts and their application in peripheral nerve regeneration. Prog. Neurobiol. 2011, 93, 204-230. [CrossRef] [PubMed] 
17. Manoukian, O.S.; Baker, J.T.; Rudraiah, S.; Arul, M.R.; Vella, A.T.; Domb, A.J.; Kumbar, S.G. Functional polymeric nerve guidance conduits and drug delivery strategies for peripheral nerve repair and regeneration. J. Control. Release 2019, 317, 78-95. [CrossRef]

18. Nawrotek, K. Current approaches to peripheral nervous tissue regeneration-mimicking nature. A review. J. Res. Innov. Nat. Med. Health Sci. 2015, 1, 16-33.

19. Piotrowicz, A.; Shoichet, M.S. Nerve guidance channels as drug delivery vehicles. Biomaterials 2006, 27, 2018-2027. [CrossRef]

20. Lackington, W.A.; Kočí, Z.; Alekseeva, T.; Hibbitts, A.J.; Kneafsey, S.L.; Chen, G.; O’Brien, F.J. Controlling the dose-dependent, synergistic and temporal effects of NGF and GDNF by encapsulation in PLGA microparticles for use in nerve guidance conduits for the repair of large peripheral nerve defects. J. Control. Release 2019, 304, 51-64. [CrossRef]

21. Mundargi, R.C.; Babu, V.R.; Rangaswamy, V.; Patel, P.; Aminabhavi, T.M. Nano/micro technologies for delivering macromolecular therapeutics using poly(d,l-lactide-co-glycolide) and its derivatives. J. Control. Release 2008, 125, 193-209. [CrossRef]

22. Danhier, F.; Ansorena, E.; Silva, J.M.; Coco, R.; Le Breton, A.; Préat, V. PLGA-based nanoparticles: An overview of biomedical applications. J. Control. Release 2012, 161, 505-522. [CrossRef]

23. Vrignaud, S.; Benoit, J.-P.; Saulnier, P. Strategies for the nanoencapsulation of hydrophilic molecules in polymer-based nanoparticles. Biomaterials 2011, 32, 8593-8604. [CrossRef] [PubMed]

24. Ravi, S.; Peh, K.; Darwis, Y.; Murthy, B.; Singh, T.R.; Mallikarjun, C. Development and characterization of polymeric microspheres for controlled release protein loaded drug delivery system. Indian J. Pharm. Sci. 2008, 70, 303-309. [CrossRef] [PubMed]

25. Wang, Z.; Wang, Z.; Lu, W.W.; Zhen, W.; Yang, D.; Peng, S. Novel biomaterial strategies for controlled growth factor delivery for biomedical applications. NPG Asia Mater. 2017, 9, e435. [CrossRef]

26. Ortega-Oller, I.; Padial-Molina, M.; Galindo-Moreno, P.; O’Valle, F.; Reyes, A.B.J.; Peula-García, J.M. Bone Regeneration from PLGA Micro-Nanoparticles. BioMed Res. Int. 2015, 2015, 415289. [CrossRef]

27. Nawrotek, K.; Rudnicka, K.; Gatkowska, J.; Michlewska, S.; Pearson, B.L.; Płociński, P.; Wieczorek, M. Ten-eleven translocation methylcytosine dioxygenase 3-loaded microspheres penetrate neurons in vitro causing active demethylation and neurite outgrowth. J. Tissue Eng. Regen. Med. 2021, 15, 463-474. [CrossRef]

28. Lee, P.W.; Pokorski, J.K. Poly(lactic-co-glycolic acid) devices: Production and applications for sustained protein delivery. WIREs Nanomed. Nanobiotechnol. 2018, 10, e1516. [CrossRef]

29. Cohen, S.; Yoshioka, T.; Lucarelli, M.; Hwang, L.H.; Langer, R. Controlled delivery systems for proteins based on poly(lactic/glycolic acid) microspheres. Pharm. Res. 1991, 8, 713-720. [CrossRef]

30. Kumirska, J.; Czerwicka, M.; Kaczyński, Z.; Bychowska, A.; Brzozowski, K.; Thöming, J.; Stepnowski, P. Application of Spectroscopic Methods for Structural Analysis of Chitin and Chitosan. Mar. Drugs 2010, 8, 1567-1636. [CrossRef]

31. Nawrotek, K.; Tylman, M.; Rudnicka, K.; Balcerzak, J.; Kamiński, K. Chitosan-based hydrogel implants enriched with calcium ions intended for peripheral nervous tissue regeneration. Carbohydr. Polym. 2016, 136, 764-771. [CrossRef]

32. Borschel, G.H.; Kia, K.F.; Kuzon, W.M.; Dennis, R.G. Mechanical properties of acellular peripheral nerve. J. Surg. Res. 2003, 114, 133-139. [CrossRef]

33. Freier, T.; Koh, H.S.; Kazazian, K.; Shoichet, M.S. Controlling cell adhesion and degradation of chitosan films by N-acetylation. Biomaterials 2005, 26, 5872-5878. [CrossRef] [PubMed]

34. Shirvan, A.R.; Hemmatinejad, N.; Bahrami, S.H.; Bashari, A. Fabrication of multifunctional mucoadhesive buccal patch for drug delivery applications. J. Biomed. Mater. Res. Part A 2021, 109, 2640-2656. [CrossRef]

35. Pawar, V.; Srivastava, R. Chitosan-polycaprolactone blend sponges for management of chronic osteomyelitis: A preliminary characterization and in vitro evaluation. Int. J. Pharm. 2019, 10, 118553. [CrossRef] [PubMed]

36. Gorabi, A.M.; Kiaie, N.; Khosrojerdi, A.; Jamialahmadi, T.; Al-Rasadi, K.; Johnston, T.P.; Sahebkar, A. Implications for the role of lipopolysaccharide in the development of atherosclerosis. Trends Cardiovasc. Med. 2021. [CrossRef] [PubMed]

37. Rothman, S.; Cowan, W.M. A scanning electron microscope study of the in vitro development of dissociated hippocampal cells. J. Comp. Neurol. 1981, 195, 141-155. [CrossRef] [PubMed]

38. Lee, J.Y.; Bashur, C.A.; Gomez, N.; Goldstein, A.S.; Schmidt, C.E. Enhanced polarization of embryonic hippocampal neurons on micron scale electrospun fibers. J. Biomed. Mater. Res. A 2010, 92, 1398-1406. [CrossRef] [PubMed]

39. Orecchioni, M.; Ghosheh, Y.; Pramod, A.B.; Ley, K. Macrophage Polarization: Different Gene Signatures in M1(LPS+) vs. Classically and M2(LPS-) vs. Alternatively Activated Macrophages. Front. Immunol. 2019, 10, 1084. [CrossRef]

40. Salomão, R.; Martins, P.S.; Brunialti, M.K.C.; Fernandes, M.D.L.; Martos, L.S.; Mendes, M.E.; Gomes, N.E.; Rigato, O. TLR signaling pathway in patients with sepsis. Shock 2008, 30, 73-77. [CrossRef]

41. Gensel, J.C.; Zhang, B. Macrophage activation and its role in repair and pathology after spinal cord injury. Brain Res. 2015, 1619, 1-11. [CrossRef]

42. Donnelly, D.J.; Popovich, P.G. Inflammation and its role in neuroprotection, axonal regeneration and functional recovery after spinal cord injury. Exp. Neurol. 2008, 209, 378-388. [CrossRef]

43. Nathan, C.; Ding, A. Nonresolving inflammation. Cell 2010, 140, 871-882. [CrossRef] [PubMed]

44. Susaki, Y.; Shimizu, S.; Katakura, K.; Watanabe, N.; Kawamoto, K.; Matsumoto, M.; Tsudzuki, M.; Furusaka, T.; Kitamura, Y.; Matsuda, H. Functional properties of murine macrophages promoted by nerve growth factor. Blood 1996, 88, $4630-4637$. [CrossRef] [PubMed]

45. Williams, K.S.; Killebrew, D.A.; Clary, G.P.; Seawell, J.A.; Meeker, R.B. Differential regulation of macrophage phenotype by mature and pro-nerve growth factor. J. Neuroimmunol. 2015, 285, 76-93. [CrossRef] [PubMed] 
46. Zhou, Z.; Yao, Q.; Li, L.; Zhang, X.; Wei, B.; Yuan, L.; Wang, L. Antimicrobial Activity of 3D-Printed Poly(ع-Caprolactone) (PCL) Composite Scaffolds Presenting Vancomycin-Loaded Polylactic Acid-Glycolic Acid (PLGA) Microspheres. Med. Sci. Monit. Int. Med. J. Exp. Clin. Res. 2018, 24, 6934-6945. [CrossRef] [PubMed]

47. Nawrotek, K.; Grams, J. Understanding Electrodeposition of Chitosan-Hydroxyapatite Structures for Regeneration of TubularShaped Tissues and Organs. Materials 2021, 14, 1288. [CrossRef]

48. Porstmann, B.; Jung, K.; Schmechta, H.; Evers, U.; Pergande, M.; Porstmann, T.; Kramm, H.J.; Krause, H. Measurement of lysozyme in human body fluids: Comparison of various enzyme immunoassay techniques and their diagnostic application. Clin. Biochem. 1989, 22, 349-355. [CrossRef]

49. Nawrotek, K.; Tylman, M.; Rudnicka, K.; Gatkowska, J.; Wieczorek, M. Epineurium-mimicking chitosan conduits for peripheral nervous tissue engineering. Carbohydr. Polym. 2016, 152, 119-128. [CrossRef] 